\title{
Current Advances In The Nanofiber (NF) Based Polymer Composites
}

\author{
Anamika CR ${ }^{1}$, Parvathy ${ }^{1}$, Sasikanth $\mathrm{SM}^{2}$ \\ ${ }^{1}$ Amrita School of Arts and Science Vallikavu, Kerala 690525 \\ ${ }^{2}$ Department of physics Noorul Islam Centre For Higher Education Kumaracoil, Tamilnadu 629180 \\ *Corresponding author: vishnusasikanth@gmail.com
}

Article History:Received:11 november 2020; Accepted: 27 December 2020; Published online: 05 April 2021

\begin{abstract}
Nanofiber (NF) polymeric composites have received more interest nowadays. The majority of the study focuses on characterizing NF and comparing them to traditional composites in terms of mechanical behavior and usage efficiency. There are different varieties of NFs, each with unique possessions that influence whether or not they are used in particular industrial usage. Because of the natural source of these materials, they have an extensive variety of characteristics that are largely dependent on the gathering position and conditions, assembly it tough to choose the right fiber for precise usage. This study aims to map where every form of fiber was located in numerous assets by providing a detailed analysis of the characteristics of NF employed as composite-based materials reinforcement. Recent research on emerging forms of fibers was also discussed. A bibliometric analysis of NF composite applications is discussed. A future trend analysis of NF applications, as well as the essential innovations to extend their uses were also addressed.
\end{abstract}

Keywords: NFs; Green-based composite; Bio-composites; Reinforcement fibers; Mechanical properties and Automotive and industrial uses.

\section{Introduction}

Even though organic resins are being used as a gluing material, the creation of fiber composites started when researchers discovered plastics. Synthesized plastics like vinyl, polythene, phenolic, and polyester are created in the early 1900s. Even so, due to lower strength, plastics were unable to meet such applications as load shifting parts of cars, aircraft, sporting goods, wind turbine blades, and other similar technologies; as a result, reinforcements were designed to enhance the qualities. The $1^{\text {st }}$ Fiber Reinforced Composite (FRC) were produced in 1935, but due to the need for composite materials throughout World War II, fiber composites underwent a substantial evolution. Following WWII, various resins and synthetic fibers were uncovered in the 1970s, fully changing the typical material use [1]. Because of their unique mechanical characteristics in different applications, synthetic fibers such as glass, coal, and aramid fibers were the utmost communal promising adsorbent in polymer-based composites [2]. Synthetic fibers are appealing because of their material properties, but they are non-biodegradable and cause further environmental concerns [3]. In the quest for synthetic fiber alternatives, bio reinforcing NFs (NF) was discovered to be an auspicious substitute for synthetic fibers in the preparations of Fiber-Reinforced Plastic (FRP) composites because of its accessibility, renewability, costeffective, and strong unique features $[4,5]$.

NF is lower in cost, density, and weight, as well as being environmentally friendly and posing few health risks. $\mathrm{NF}$ is assumed to be worth using in the production of composites not just in terms of environmental and economic benefits, but also because these were recycled raw processes for novel green goods. NFs' biological, chemical, ecological, and economic characteristics can greatly enhance the ending features of fiber-based composite and its use in numerous application areas. NF degradation rate will strongly help the recyclability feature of fiber composites. NF degradability will sturdily sustenance the recyclability property of fiber-based composites, thus promoting the production of NF reinforced polymer (NFRP) [6]. NFRP has a lower density, resulting in lighter composites [7]. As a consequence, there is an increasing interest throughout the commercial usage of NFRP in diverse industries.

NF was collected from leaves, roots, vegetables, and seeds, among other parts of the plants. The use of the Fiber reinforced composite (FRC) has improved gradually in recent times in several applications. These composite materials were now being utilized in new fields like medicinal devices and civil structures [8]. Fiber reinforcement comes in a variety of shapes and sizes of composites. From an environmental standpoint, NF composites were larger than glass-based fiber composites [9]. NF selection is the utmost critical method in the processing of NFRP composites in particular. NF selection is affected by a variety of factors. NF is selected based on its physical characteristics. The age of floral was a key feature in evaluating NF output [10]. The chemical-based composition of the fiber differs by origin; the most common additives were cellulose, hemicellulose, and lignin; however, another additives including ash, wax, and pectin were available [11].

One of the problems with NF is the lack of consistent information and mentioned distinctions in material characteristics. The lack of expertise for both creators and consumers of these materials in terms of how to collect, consider, method, and post-process natural materials further complicates the selection criteria. These 
problems are, in fact, major deterrents to the widespread usage of NF in a spectrum of uses. To fill this void, our research delivers a review of various mechanical features of fibers and their uses. This study was divided into four stages: first, we deliver a summary of NFs, emphasizing their advantages and physicochemical characteristics. The appropriate applications and future trends are then described. Eventually, we analyze and make some conclusions with some remarks.

\section{Reinforced natural biological composites}

Biological composites could be categorized as partly environmentally or green, based on the level of the components (Figure 1). All of the components of a green composite are made from recycled materials, potentially lowering $\mathrm{CO}_{2}$ emissions and reduce the need for fossil fuel materials. Whilst partially environmentally, including some of the components, fiber or matrices, is not made from recycled materials [12]. The number, thickness, shape, and structure of the fibers, as well as their contact angle with the matrices, all impact the behavior of NF [6].

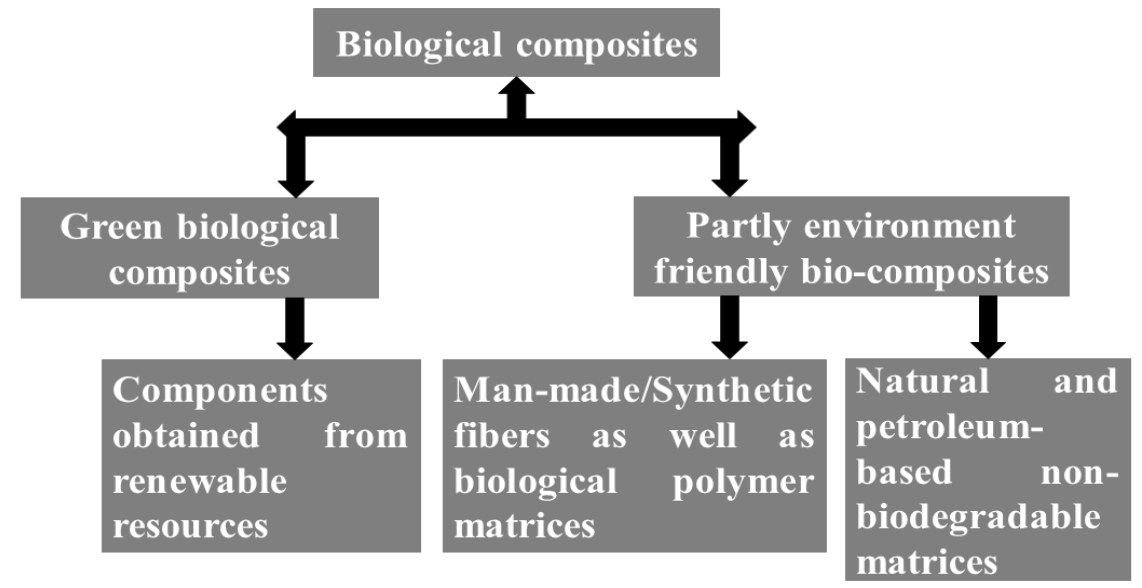

Figure 1. Various forms of biological composites.

As illustrated in Figure 2, NF reinforcing could be classified into three forms based on length, size, and direction. This may take the shape of a fiber or a particle. The length-to-diameter (1/d) proportion of the fiber dictates whether it is continuous or discontinuous (means sliced). The woven or non-woven fiber-reinforced step structure is the most common classification. A piece of woven fabric is defined by a predictable pattern of constant interlacing of perpendicular yarns. Yarns are structures made up of a variety of entangled fibers. The twist angle is essential for fiber cohesion and yarn stability up to a limit, after which the overall fiber strength reduces due to increased obliquity [13]. Furthermore, raising the fiber twist angle is connected to weaker fiberresin mechanical properties, permeation, and, as a result, poor mechanical properties [14]. The fiber architecture can have more than one dimension when continuous fibers are used [15]. The twist angle and degree of orientation of continuous-filament yarns contribute significantly in deciding the overall applied force in the onedimensional structure. As a consequence, unidirectional composite materials are slightly lesser in transverse directions $[6,13]$. Given these features, anisotropic frameworks can have a minimum of three to four times good mechanical strength than the isotropy equivalents for a specified state of stress [16].

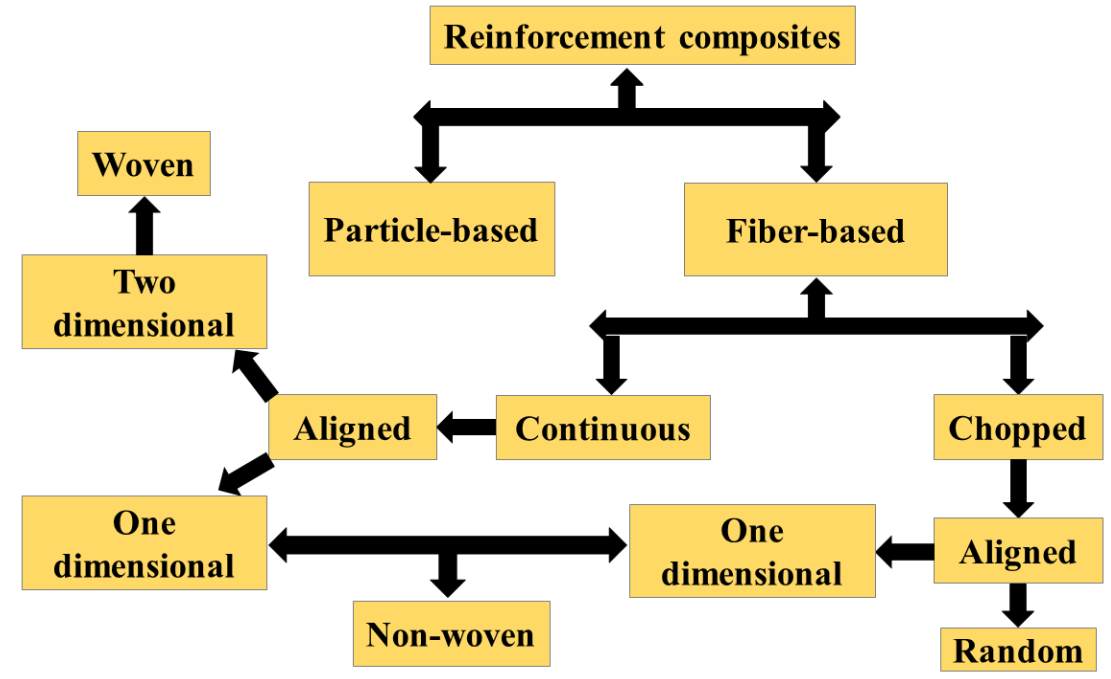

Figure 2. Categories of natural-based fiber reinforcements. 
The mat/woven could either be comprised of constant or sliced uni-directional fibers, arbitrarily sliced fibers, or particulate matter [15, 17]. A non-woven framework is a flat assembly lacking interwoven elements, composed of a mat laterally or arbitrarily focused and put together to use heat, chemical, pressure, or a mixture of this as an adhesion-based promoter, these could either be comprised of consistent or sliced uni-directional fibers, spontaneously sliced fibers, or deferred elements. Mats made up of randomly chopping fibers (whiskers) in specific do not have a preferred stress path, and they're the preferred option for larger-scale development owing to their higher availability, simplicity, and cost efficiency when producing complex isotropic components [18]. Several studies have shown that NF can serve as reinforcing materials for non-performance and semi-structural components. In reality, to boost fuel efficiency, the automotive industry is increasingly favoring lightweight products [19], like non-structural transportation components with natural materials [20].

The role of certain advanced features to a fiber-reinforced composite includes matrix properties, fiber-matrix ratio, filler content, binding agents, and other methods for processing [21]. As a result of flaws in the production process, the poor adhesion among layers, multi-layered fiber-reinforced composite materials are vulnerable to early loss because of its delamination, that is, laminas [22].

\section{Biological-based polymer matrix}

The characteristics of the polymer matrices also influence the mechanical efficiency of a bio-composite (thermoplastic or thermoset). These materials can be made with either bio-based or artificial raw materials. In literary works, the word biological polymer has various and conflicting definitions, such as but not confined to bio-based, environmentally friendly, or both [23-26]. Other terms, while not inaccurate, such as "bio-based polymer" or "renewable-sourced polymer" is often utilized to mention polymers that contain polymers. Carbon from a green plant or biomass source [27, 28].

The commonly used definition seems to be that biological polymer is a polymer-based substance where the main constituent has a biological source and may or may not be bio-degradable [29]. Biodegradable implies that the polymer is biodegradable by the activities of living species or by non-enzyme hydrolysis [30]. It should be noted that not all biologically degradable materials were compostable [29].

Biopolymers constitute an incredibly small proportion of the world's demand for polymers, approximately $6 \%$ [31]. Evermore market diffusion heavily is contingent on a variety of variables, like feedstock rates, crude prices, technology viability, favorable regulatory changes, and policies [32, 33]. The collection of polymeric composites requires a previous analysis of mechanical characteristics, chemical tolerance, dimensional stability, synthesizing techniques, often with an emphasis on potential recycling or biodegradability. End-of-life reusing efficiency is based on the heterogeneous behavior of the components.

On the one side, thermosets also have a broad array of uses because of their strong adherence, higher thermal and chemical-based resistance, and high mechanical strength. But on another side, in comparison to thermo-sets, -plastics may be molten. When hot, Van der Waals and $\mathrm{H}$ bonds are partially smashed, enabling molecular maneuverability. Thermoset matrix is still hard to reuse and recycle, but some reports have stated that thermosetting polymers can be reutilized [33]. Further research indicates that a more eco-friendly sustainable product may be accomplished by the use of biologically degradable fillers [34].

\section{Natural-based fiber composites}

Figure 3 exemplifies the formation mechanism of nano-based biological composite (NBC). NF is commonly present in nature and was exists throughout the globe. NF-based composite materials are now increasing as common daily and are replaced by synthetic fiber-based composites because of their excellent biological degradability (Figure 4), renderability, decomposability, toughness, improved length-to-weight proportion and lower cost [35, 36]. NF is classified into 4 major classes: seed, leaf, bast and stalk fibers [37]. Cotton stalk, kenaf, and flax fibers, etc are commonly used plant-based reinforcers [38]. The chemical constituents of such various biological fibers including, cellulose, hemi-based cellulose, phenol-based substances exist in lignin and pectin, substantially affect the effect of the composites. 


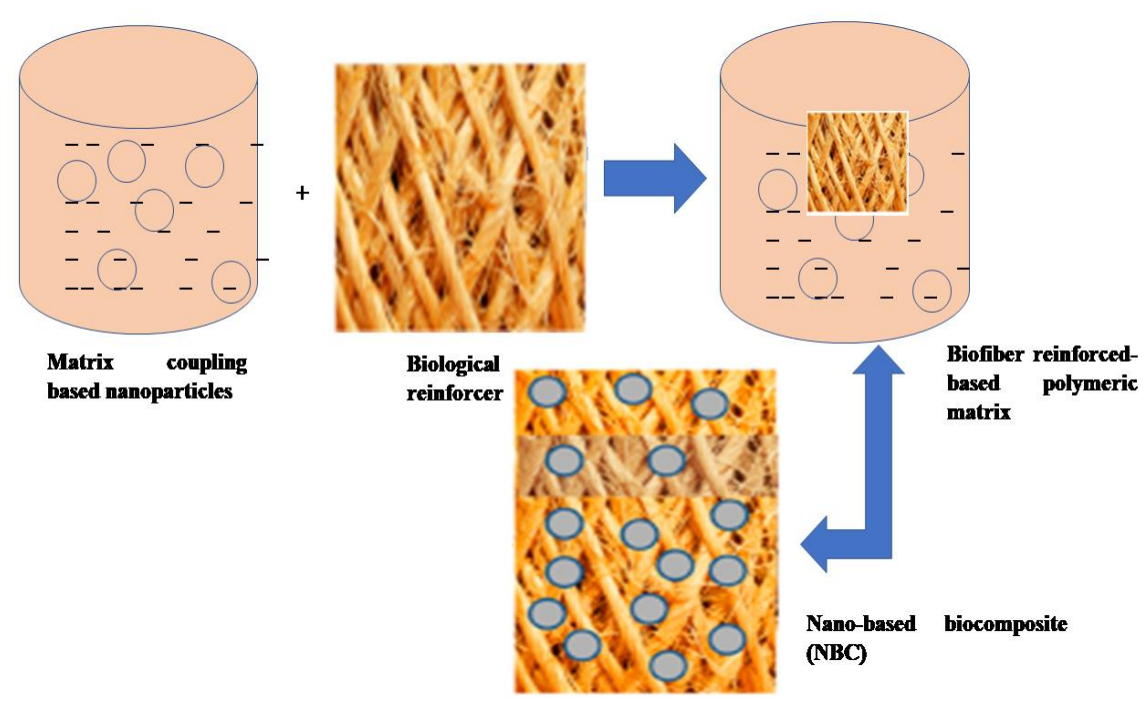

Figure 3. Formation mode of action of NBC.

Cellulose, major chemical-based element of total NF based on plants. It's the utmost remarkable natural substance provided by floras which are abundant in the atmosphere. Cellulose consists of a longer network of glucose polymeric units which are bound with each other to produce microfibrils.

Hemp, the quickest increasing natural plant and it is widely utilized for construction materials and textile-based fibers $[39,40]$. Hemp-based fibers were biologically degradable, plentiful in nature and sustainable. Hemp fiber BCs were used as eco-friendly, economical and renewable resources in automotive panels for a long time. Nanomaterials have a significant part to play in improving the asset of cellulose fibers. Also, NPs may improvise the mechanical features of NBCs by integrating them into cellulose-based fibers (like hemp), synthetic additives and tributyl citrate plasticizers. Studies on NBC's developed by strengthening hemp fiber and $\mathrm{SiO}_{2}$ by polylactic acid were undertaken to explore thermo-mechanical performance. The effective and proper distribution of silica-based NPs has ensued in greater mechanical characteristics.

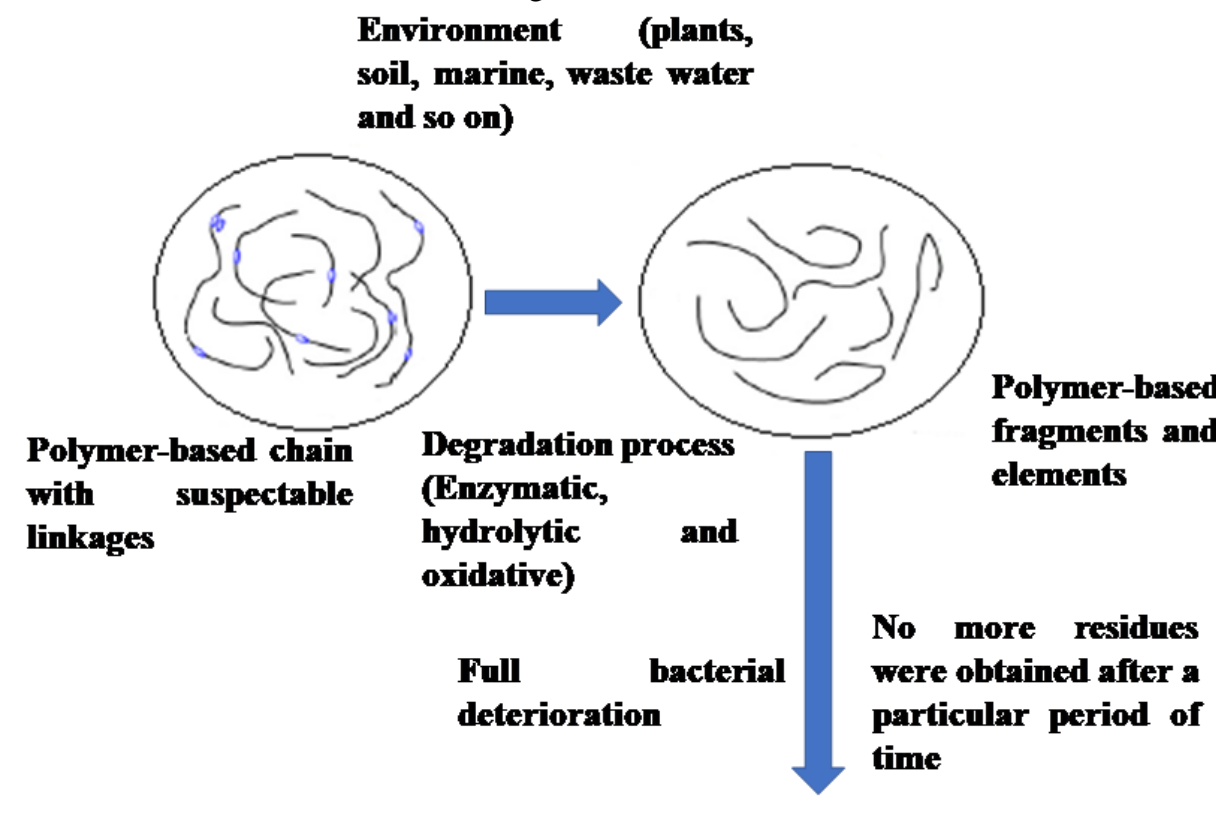

Carbon di oxide + Water + Cellular biomass

Figure 4. Biological degradation of biofiber-based composites.

Coir fiber was formed through the outer side of the leaf in coconut. Coir was utilized to manufacture a range of environmentally safe and biodegradable goods for commercial, manufacturing and house-hold uses. It is widely used in mats, geo-textiles, sacking, gardening, and automobiles. In the part of reducing costs, coir may be the perfect alternative for replacing glass fibers to create thermoplastic reinforced composite materials because of remarkable material characteristics. The larger proportion of coir content (60 percent) raises the tensile (35 percent) and flexural strength (26 percent) of coir or polypropylene reinforcement [41]. Nevertheless, the enhanced fiber substance (coir) has a negative impact on internal interfacial bonding and water resistance [41]. 
Coir fiber has a very strong ability to withstand moisture, saltwater and heat. Consequently, in the future, coir may be a possible candidate for NBC output.

Flax fibers were typically harvested from the stem that was a certain period higher than cotton [42]. Flax, a suitable replacement for inorganic fibers for the production of NBC's. Flax fibers have excellent mechanical features compared to glass-based fibers. Furthermore, the thickness of the lining is about half that of the glassbased fibers. As a result, when composite materials are produced by flax fibers, it possesses a lightweight and greater strength than inorganic materials [43]. Flax fiber-based composites consisting of thermo-plastics, -sets and bio-degradable show amiable mechanical properties [44]. Flax fiber is capable of being reinforced by graphene NPs to manufacture lower-cost and possible NBCs via multi-faceted processing ways. Enhanced flame retardance and tensile strength (61 percent greater than the nanofiller-free case) were however recorded for graphene reinforced by flax or epoxy-based composites [45].

Cotton, commonly utilized cellulose fiber in the globe. When cotton was reinforcing through PLA to produce $\mathrm{BCs}$, it showed higher mechanical behavior, with dramatic enhancements in tensile behavior and Young's modulus, with no reduction in deformation only at the point of rupture [46]. Cotton burs may be a possible replacement/alternative for post-thermal processing in blend-based composites instead of other agri-based floral fibers that improve density, swelling and $\mathrm{H}_{2} \mathrm{O}$ absorption [47]. Cotton, the ability to be employed as an effective reinforcement for the manufacture of lower-cost composites. Better thermal stabilization of the $\mathrm{BC}$ has been documented to enhance the adhesion among cotton as well as the polymer-based matrix by reducing the entrée of the oxidized gas to the boundary [48].

Ramie, green, operational bast fiber by a silky texture, greater absorption, air-permeable and smaller line features. Gummy substances attained from ramie-based fibers must be filtered via a de-gumming method before successful industrial production can take part [49]. It is one among the greatest bio-degradable, NF with higher asset and antimicrobial and fire retardant characteristics [50, 51]. Poly(lactic acid) (PLA), fragile that restricts the use of PLA-based polymers, however, the reinforced NF (like ramie) or nanofiller might decrease this impact and boost the physicochemical characteristics. The surface pre-treatment of fiber has also increasing poplar to greatly improve the mechanical features of biological composites. Throughout this regard, ramie fiber was treated by silane (a) 1 , which exhibited strong tensile strength, impact strength, and flexural strength on PLA or ramie-based materials [52].

Sisal has a strong stiffness, toughness and tolerance to salty $\mathrm{H}_{2} \mathrm{O}$, that's why it was used for a longer period in twines, cords, paper, filters, and carpets. Few of the exceptional merits of utilizing sisal-based fibers were linked to (1) lesser density, (2) non-abrasive nature, (3) low cost, (4) less energy consumption, (5) greater capacity for filling, (6) higher bio-degradability, (7) greater effective features and (8) the development of an agriculture sector in rural areas [53].

Agave, another potential NF which, due because of its reproducibility, low weight and economic factors, receives attention from both researchers and manufacturers. Although raw agave fibers might show a major part in the improvement of reinforcement possessions, few fiber pre-treatment methods have been developed to influence better impacts $[54,55]$. The elasticity modulus of fiber composite from agave-based fibers tends to increase by a high swelling \% of fiber component; the same phenomenon was also ascertained for the crop strength properties of agave or higher-density polyethylene and agave/Polypropylene-based (PP) materials [56]. The synthesizing technique, substances for matrices, and uses of few broadly utilized biological polymers were enlisted in Table 1. 
Table 1. Use, production technique and matrix substances of few potential natural-based fibers.

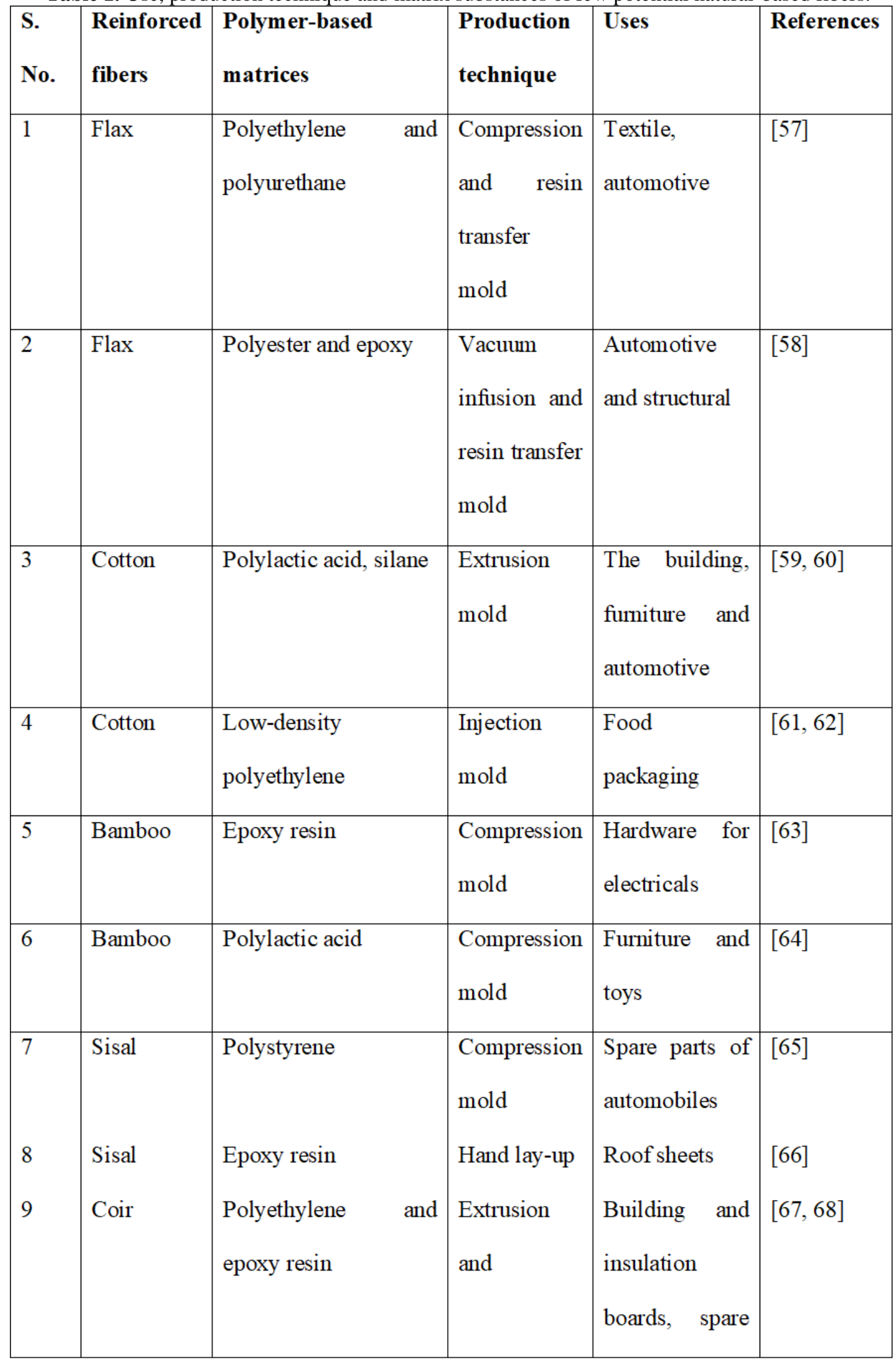

Polymers are comprised of several repetitive subunits, like monomers, which were chemically attached. They are primarily divided to two types: natural-based polymers (such as cellulose, pectin, collagen, lignin, and hemicellulose) and inorganic polymers (such as polyethylene terephthalate (PET) and LDPE, etc.,). Another forms of 
altered natural-based polymers, like viscose, were also present. BCs are presently attracting considerable attention due to its bio-compatibility and -degradability creating them potent substitutes for petroleum-based plastics [71].

\section{Polymer-based matrices}

A matrix keeps all the reinforcement fibers and products with each other in a framework to transfer or share some exterior stress inside the components to provide protection towards another degrading phase, whether in a mechanical (flying debris, delamination, extreme temperatures, flushing and $\mathrm{H}_{2} \mathrm{O}$ absorption) or a chemical process. The matrices were often referred to as the base metal and shows a crucial part in composites bearing tension forces in the structure [72, 73]. There were 4 significant types of matrix: (1) metal, (2) polymer, (3) carbon and (4) ceramic-based. The utmost commonly utilized matrix in industrial companies were polymer resins, especially thermo-set polymers and -plastics. Thermoset matrix were interlinked and during the brewing procedure. The crosslinking was created by heating or through adding curing substances. As a result, thermoset plastic will tougher and stirrers, making them an enticing polymer-based matrix in conventional fiberreinforced, like carbon or fiber-based materials. Polyester, epoxy resin, polyamide, novolac, poly-urethane, urea-formaldehyde and vinyl esters were common polymer thermosets. Thermoset polymers are made by extrusion-, reactive inoculation, spinning casting, and compression molding [74, 75].

Alternatively, thermoplastic plastics are produced of plastic polymers which need a suitable $\mathrm{T}$ for manufacturing and maintain a solid-phase after freezing. The molecular mass of thermoplastics is very large and the functional groups were linked by molecular interactions. The main benefit of these material which could be microwaved again, without any substantial deviations in the particular characteristics, for any such reorganization. PP, PLA, acrylonitrile butadiene styrene and so on are good examples of thermoplastic polymers. Calendaring, extrusion, injection, and injection molding are some of the manufacturing methods available to continue providing precise shapes for thermoplastic polymers [76, 77].

\section{Natural Filler Reinforced Polymeric nanobiocomposite (NBC)}

Fillers are natural or synthetic materials that contribute to composites in the type of particles, fragments, fibers, sheets, and whiskers. For the past 3000 years, lignocellulosic fibers, along with many other polymeric components, have been used as fillers as a reinforcement element [78, 79]. Nanofillers have rarely been described as a promising component for improving the polymeric features and mechanical efficiency of NBCs. Researchers and suppliers are currently pursuing cheaper, thinner, heavier, and smaller composites in the hopes of achieving such nanosheets in a superior selection of materials [80, 81].

When the volume of a bigger area polymer matrices were reduced to a tiny region within the nm range, several versatile functionalities seem together with outstanding mechanical asset in comparison with raw or non-nanotreated materials [82]. One of its main advantages of NP-incorporated BCs which they can change behavior at higher temperatures without altering manufacturing circumstances and melting temperatures [83]. Thermoset polymers are brittle when crystallized. The problems could be solved by adding biological fibers and nanofillers $[84,85]$. Nanofiller grafting also raises the thickness of composites, resulting in improved hardness in NBCs. Furthermore, NF has better basic properties than synthetic fibers, which increases the efficiency of NBCs when combined with some other reinforcing agent.

NBC's are generated when NPs are dispersed in the BC matrix for various functionalization activities. NMs used in NBC's are usually less than $100 \mathrm{~nm}$ in size. As compared to conventional BCs, NBC's function best. Extensive research has recently been performed on the use of various NPs as convenient nanofillers in NBCs [86-88] while preserving sustainable development. Biofibers and matrix can simply be achieved by polymeric NBC's (thermosets, thermoplastics, and vitromers) [40, 89]. Researchers have invented a variety of processing conditions for obtaining biological functions by combining various polymeric components into matrixes and reinforcing them with different clays.

\section{Fiber characteristics}

Properties of a mono fiber are based on the figure, dimension, crystallite content, direction, and density of cellular walls [90]. The major features of NF were lower energy-based consumption, less thickness, nonabrasive nature, lower cost, renewable, biodegradable, easily available, and around the world [91]. Though plant-based fibers were typically rigid, unlike brittle synthetic-based fibers, they were not fractured throughout processing [92]. Plant-based fibers possess equivalent particular strength and stiffness characteristics to glassbased fibers [92]. Bast fibers were removed from the stem ribbon utilizing a retting method. These kind of fiber has higher tensile strength and stiffness; costly, possesses higher performance, and was widely accessible [90]. When power, lighter-weight, and noise absorption are essential, like those in the automotive and construction industry, this fiber is more suitable. Except for those developed in temperate zones with heavy usage of agrochemicals (e.g., flax), most plant-based fibers were classified as eco-friendly fibers since they were environment friendly and are not harmful impact on the atmosphere [90]. Animal fibers, but on the other hand, get a lower stiffness that is offset by their higher elongation and elastic recovery [90]. They're also low 
hydrophilic than plant-based fibers, more resilient with mild resistance, lower thermal conductors, sensitive to certain alkalis, and capable of multi-axial reinforcement [90].

The cellular membranes of dried floral fibers were mostly made up of lignin and sugar-based polymers, by a slight amount of starch, extractives, receptor, and inorganics thrown in for good measure [90]. Under natural conditions, cellulosic fibers are hydrophilic (moisture absorbent). The mechanical behavior of NF composites can be influenced by the water content of the fibers.

\section{Green composites-based matrix}

In composites the matrices were utilized to keep the reinforcing substances collected by surface connections. The matrix is primarily responsible for the composite's environmental resistance, surface appearance, and longevity [90]. When the matrices were strained, it evenly distributes the exterior load to the fibers and was used to prevent cracks and damage from spreading [90]. Because of dwindling fossil fuel supplies and the surrounding effects of utilizing petroleum-based matrix, several investigations have been performed in the latest years to explore an alternative to the traditional petroleum-based matrix [93].

\section{Petrochemical-based resins}

These are a chemical substance made from petroleum that comes from fossil fuels such as coal and natural-gas [93]. Thermo-plastics and -sets are the two main forms of petrochemical-based matrices used in composite materials. Thermoplastic matrices include polyethylene, polystyrene, polypropylene, and polyvinyl chloride (PVC), while thermoset matrices like epoxy and phenolic, etc. [90, 93].

\section{Thermoplastics}

Thermoplastic resins are made up of viscous polymers which can be easily formed and solidified by cooling [94]. The conductivity of thermoplastic resins throughout the melted state is nearly 500-1000 times those of uncured thermoset-based resins [93]. They were stable at room $\mathrm{T}$ and could be redefined and redesigned without causing chemical-based reactions once heated [93]. Thermoplastic resins outperform thermoset resins in terms of impact resistance (roughly ten times), reformability, harm tolerance, and manufacturing temperatures and pressures [90].

\section{Thermosets}

Thermoset resins are heat or catalyst-cured insoluble and infusible materials [95]. Thermosets are not the same as thermoplastics in that they cannot be melted and redefined with heat [96]. This form of resin have a greater modulus, enhanced creep tolerance, greater temperature stability, and better chemical-based tolerance than thermoplastic resins due to 3D covalent bonding among the polymeric network [97]. At room temperature, they are therefore fragile and have poor fracture toughness.

\section{Biological resins}

They [90] were polymers made entirely or partly from renewable materials. Plant-based polymeric materials and plant-based sugars and oils are examples of bio-based polymers [93]. There are 3 types of biology-based polymers because of its physical characteristics: completely biodegradable like polyhydroxyalkanoates (PHA) and starch, partly environmentally friendly and recyclable, such as cellulose and PLA, and partly biological based and non-bio-degradable, such as bio-polyethylene terephthalate, -polyethylene, and so on [90, 93]. According to reports, nearly 3.5 million tonnes of biology-based polymers are manufactured globally in 2011, compared to 235 million tonnes of conventional petrochemical-based polymers [90]. The production of biobased polymers has increased at a rapid pace in recent years, with estimates that it will exceed nearly 12 million tonnes/year by 2020 [90]. These number, however, is substantially lesser than that used to produce petrochemical-based polymeric materials, and it required to be raised even furthermore to reduce the -ve atmospheric effects of petroleum-based substances [90]. In comparison to petrochemical-based polymers, it's been shown that certain forms of PLA made from maize, starch using nearly $50 \%$ less oil and emit $60 \%$ less greenhouse gasses for the same uses [90].

Completely bio-based and environmentally friendly materials possess renewable carbon that is extracted from the atmosphere and added to it as the polymer evaporates [93]. This renewable fuel can be collected by gathering polymers typically employed for disposed cutlery and elastic food packing that are discarded amid food wastage [90]. Drop-in biology based polymers, such as biological polyethylene terephthalate, can be reused in the same way that petrochemical-based materials can [90]. When recycling isn't an option, this form of the polymer could be burned to produce renewable energy. Bio-based resins have many benefits over petroleum resins, including being more energy effective in manufacture (requiring 65 percent less energy), safe, decomposable, entirely sustainable, and eco-friendly (producing 68 percent fewer greenhouse gases) [98]. That being said, their manufacturing costs are around $10 \%$ greater than those of petrochemical-based resins [99].

\section{Mechanical properties of NFs}

Plant photosynthesis produces $10^{12}$ tonnes of cellulose each year in the bio-sphere, rendering polysaccharides the world's greatest natural carbon reservoir [100]. The most commonly identified cellulose-dependent NF can be classified based on the flowering plants and tissue utilized [101-103], such as bast, leaf, seed, berries, and stalk [101-103]. Plant-based NF is typically take out from the floral substance after it has been retted or 
decorticated to eliminate unwanted cell membranes. Plant development, harvesting and refining, fiber isolation, and distributing are all stages involved in the production of NFs [104]. Many considerations, with physical characteristics, chemical properties, crystal cellulose dimensions, microfibrillar angle, faults, structure, and isolation process, complicated the characteristics of NF, even when it comes from the same plant source. As a result, the fiber's consistency and mechanical properties will vary significantly. These NF have a wide range of tensile strengths and moduli, with the usual tensile strength in them.

\section{Natural reinforced fiber composites}

For NFs, both thermoplastic and thermoset composites were used as matrices. Since most NF is not thermally stable above $200^{\circ} \mathrm{C}$, a matrix of softening thermoplastics and thermosets which can be cured underneath this temperature is chosen [105]. Four forms of matrices have been commonly used only for NFRCs owing to thermoplastics' simple recycling ability. In the following pages, the automatic characteristics of fiber-reinforced composite materials were addressed briefly.

\section{Natural-based fiber-reinforced polypropylene}

Along with its manufacturing suitability (viz., filling, strengthening, and blending), accessibility, lower heat distortion T, clarity, flame tolerance, and dimensional stability, PP has commonly used it as a framework for NFRCs [106]. Though its elastic modulus and compressive strength of NF/PP composites vary widely, based on its fiber component and integration approaches, integrating NF will massively improve the matrix's modulus of elasticity and tensile strength. Many NFRCs by fiber contented greater than $30 \mathrm{wt}$ percent have achieved advanced tensile elastic moduli values when compared to a tensile strength of $20 \mathrm{wt}$ percent longer glass fiberreinforced PP stated for inner uses by Ford Motor Company [107]. The strength properties of NFRCs, on the other hand, are significantly lesser than those of these glass fiber or PP hybrid that has been due to NF unsuitability with the matrix in the past. The low tensile strength of NF compared to glass fiber may also be attributed to its poor transverse mechanical properties.

Bamboo fiber has a stronger mixture of wetting criteria (for instance stronger work of adhesion, better dispersion coefficient, relatively high wetting stress, and low interfacial energy) than glass-based fiber, showing a greater physio-chemical consistency by PP [108]. Glass fiber, on the other hand, had a stronger interfacial adhesion power in the composites, as shown by both a greater electrical local interfacial shear yield-and radial normal-stress only at the time of crack beginning, explaining why bamboo fiber's overall output in reinforcing PP was lower than glass fiber's. This finding backs up the theory that NF's anisotropic existence is the primary cause. This finding backs up the hypothesis that NF's anisotropic behavior is the key explanation for an inferior interfacial features and strain transfer capacity at the fiber or matrix interfaces as a comparison to glass fiber. The transverse and shear moduli of jute fiber are an order of magnitude smaller than the longitudinal modulus, according to Thomason [109]. As a result, the poor elastic performance of NFRC compared to glass-based fiber-reinforced composites analog was principally leading to decreased material characteristics in the transverse way due to possible detachment of an outer layer and basic fibers in connection with both the matrices, which occurs frequently during compound growth and extrusion, rather than on the chemical and physical consistency between the two materials.

\section{Uses of NFs}

In an automotive industry, NFRCs are commonly used. It is calculated that $75 \%$ of fuel efficiency is necessarily correlated to vehicle weight, by every $10 \%$ decrease in vehicle wt resulted in a 6-8\% rise in fuel economy, and every $100 \mathrm{~kg}$ wt savings in automotive results in a CO2 emission reduction of roughly $15 \mathrm{~g} / \mathrm{km}$ for widely used powertrains [110]. Weight loss explicitly contributes to the European Commission's and European Automobile Manufacturers Association's $\mathrm{CO}_{2}$ emitted mitigation goals [111, 112]. The Corporate Average Fuel Efficiency requirements in the United States mandate automakers to raise the fuel effectiveness of cars and trucks to 54.5 miles/gallon by 2025 [55].

Many other countries have implemented similar laws to boost fuel efficiency and CO2 reduction [112]. Ford Motor Company considered using bio-based materials in automotive components as early as the 1930s, and there have been many highlighted uses of NFRCs within the automobile industry until now [111, 113]. For instance, in 2000, Audi introduced the A2 midrange car that featured flax or sisal-reinforced PU door trim panels, and Mercedes-Benz revealed the first flax/polyester engine and transmission kennels for standard exterior substances. Porsche revealed in 2019 that the 718 Cayman GT4 Clubsport racecar was the world's first automobile by hemp or flax-reinforced composite bodywork.

Government legislation in Europe and North America has favored the use of NFRCs throughout the automotive industry in recent decades. Manufacturers and suppliers were progressively using "green" composites generated from NF in automotive parts like door panels, seat backs, dash-boards, and inner portions. Flax- and sisalreinforced thermosets have conquered among such plentiful NFRCs for automotive applications. Bio-based composites have been used by BMW, Ford Motor Corporation, General Motors, Benz, and Toyota in several applications. NF has been used extensively in Mercedes-Benz products across a wide range of models [114]. For instance, the A-class uses $20.8 \mathrm{~kg}$ of $\mathrm{NF}$ in over 20 elements; the B-class uses $19.8 \mathrm{~kg}$ of $\mathrm{NF}$ in over 21 elements; the C-class uses $17 \mathrm{~kg}$ of NF in over 27 components, and the D-class uses $21 \mathrm{~kg}$ of NF. Since the 
mid-nineties, BMW has used NFRCs in its M3, M5, and M7 series versions, utilizing up to $24 \mathrm{~kg}$ of recyclable sources.

Due to various their inherent moisture sensitivity and lower mechanical properties, NFRCs are widely used in interior automobile components. Indoor panels, dashboards, box shelves, and storage bins are all instances of the nonstructural interior that can contain NFRCs. Flax/polyester composite materials for soundproofing in the engine and transmission enclosures, abaca-reinforced composites for spare tyre well covers, fender parts, spoilers, bumpers, seat frame, and load floors are only a few instances of NFRCs used for exterior components in a performance car. New NFRC tests, such as flax/Acrodur with implanted flax tape at short, have recently been released. New research on NFRCs has barely been touched, including flax/Acrodur composites with impregnated flax tape for quick molding parts in automobiles [115], flax/vinyl ester composite materials for automobile hoods [116], hemp/PP composites resistant weathering for interior and decking parts and tiny auto parts [117, 118], kenaf/epoxy composite materials for spall liners [119, 120], maple and pine flour-reinforced NFCs. It is beneficial to conduct innovation and education to expand the applications of NFRCs to more structural elements.

NFRCs have lately been developed for their uses in masonry, soil blending, cementitious materials, heat insulation materials, furniture, and decks applied in civil building, furniture, and architecture due to their lighter weight, low thermal conductivity, and lower environmental effects of renewable materials [124]. Such composite materials, on the other hand, are typically limited to thin sheet applications with a high fiber volume fraction, rendering them unsuitable for constructing structures. NF composites have mainly been investigated for possible applications in sports, clothing, recreation facilities, aerospace, medicinal, and other fields. NF composites having previously been reviewed for possible applications in sports, footwear, recreation facilities, aerospace, medicinal and medicinal, electrical, packaging, and electromagnetic uses, among others (Table 2).

Table 2. Uses of NF in various fields.

\begin{tabular}{|c|c|c|c|c|}
\hline S. No. & NFS & $\begin{array}{l}\text { Other major } \\
\text { constituents }\end{array}$ & Potential uses & References \\
\hline 2 & $\begin{array}{l}\text { Banana } \\
\text { Kenaf }\end{array}$ & $\begin{array}{l}\text { Soil and cement } \\
\text { Plaster of Paris }\end{array}$ & $\begin{array}{l}\text { Compressed } \\
\text { earth block } \\
\text { Ceiling }\end{array}$ & $\begin{array}{l}125] \\
{[126]}\end{array}$ \\
\hline 3 & Lignocellulose & Thermoplastic resin & $\begin{array}{l}\text { BioMat } \\
\text { research } \\
\text { pavilion }\end{array}$ & [127] \\
\hline 4 & Sisal & $\begin{array}{l}\text { Poly(methyl } \\
\text { methacrylate) }\end{array}$ & Drug delivery & [128] \\
\hline 5 & Jute & Glass fiber and polyester & $\begin{array}{l}\text { Solar parabolic } \\
\text { trough collector }\end{array}$ & [129] \\
\hline 7 & $\begin{array}{l}\text { Cotton } \\
\text { Oil palm }\end{array}$ & $\begin{array}{l}\text { Epoxy } \\
\text { Epoxy }\end{array}$ & $\begin{array}{l}\text { Medical } \\
\text { imaging } \\
\text { Sports usage }\end{array}$ & $\begin{array}{l}{[130]} \\
{[131]}\end{array}$ \\
\hline 8 & Flax & Carbon nanotube & Electrodes & [132] \\
\hline 9 & $\begin{array}{l}\text { Wood-based } \\
\text { cellulose }\end{array}$ & $\begin{array}{l}\text { Cobalt sulfide and carbon } \\
\text { fibers }\end{array}$ & Battery & [133] \\
\hline 10 & Hemp & Aluminum and epoxy & $\begin{array}{l}\text { Electromagnetic } \\
\text { interference } \\
\text { shielding }\end{array}$ & {$[134,135]$} \\
\hline
\end{tabular}




\section{Industrial uses}

The improved value of sustainable raw materials and product reusability or biodegradability is creating a move away from petroleum-based synthetics and toward NFin industrial applications [136]. NF composites were used in an automotive industry since the 1940 s when Henry Ford established the $1^{\text {st }}$ composite parts in a car utilizing hemp fiber [137]. The next referenced requirement was at 1950s, by the creation of the East German Trabant's chassis, and other producers, such as Daimler-Benz (1994) and Mercedes (1996) [137]. Since the market for low weight and ecologically responsible materials is increasing, NF-based composites have a lot of potential in the automotive sector. According to studies, NF composites will help reduce the cost and weight of an automobile component by $20 \%$ and $30 \%$, respectively [138]. According to those writers, lightweight components result in lower fuel consumption, better recycling choices, reduced wastage disposal, and reduced greenhouse emissions, all of that is important factors in the use of NFs. Internal parts like dashboards, door panels, parcel racks, backrests, and cockpit linings are often made of NF composites, although the usage of NF composite materials for outdoor uses are very restricted [138].

Different parts of the country cultivate and used different forms of NF, and they sometimes import or export it to other parts of the world. The European automotive industry, for example, primarily utilizes flax and hemp, while jute and kenaf were primarily introduced from Bangladesh and India, banana from the Philippines, and sisal from South Africa, the United States, and Brazil. For the German automotive industry, flax fiber is the utmost significant NF [138]. Wood polymer and NF composite materials account for 10-15 percent of the European composites industry [139].

\section{Conclusion}

Lightweight design, ecological friendliness, reusability, and mechanical performance generated from NFs are all well-known attractive properties of NF-based composites. Weight loss, energy efficiency, environmental conservation, and medical benefits can all be achieved by using NFRCs, particularly in the automotive industry. The inherent variability and hydrophilicity of NFRCs, on the other hand, face manufacturing and usage challenges. Fiber quality variability, poor fiber or matrix adhesion, harder fiber dispersal, minimal composite manufacturing requirements, and moisture absorbent are the most pressing concerns. The Discovery of new NF in large quantities can help to diversify fiber sourness. Exploration of fresh, abundant NF can help diversify fiber sources while also lowering material costs. Consistent NF consistency, on the other hand, is often an essential feature for NFRCs to perform consistently. To enhance NFs' dispersion and bonding strength with polymer matrix, as well as the material properties of NFRCs, further research into the fundamental microstructure of the interphase is required. Coupling factors and chemical modifications can greatly boost the stability of NF and polymer matrix but provided the thermo-mechanical orthotropic of the fiber, interfacial adhesion force tends to shows an important role. In turn, techniques like unidirectional fiber, mat fabric stacking, hybridization, and manufacturing revolution will dramatically boost the longitudinal performance of NFRCs. NF with superior modulus and strength, such as nano-scaled cellulosic fibers, have given rise to new reinforcement materials for polymers and could play a key role. Furthermore, 3D printing of NFRCs with specific composite design and advanced actuation efficiency has the potential to greatly change and extend the usage of NFRCs in the coming years. The future demand for NFRCs were growing, as is their use, especially in the automotive, civil engineering, athletics, and biome industries. The future demand for NFRCs is growing, and their applications, especially in the industrial, civil engineering, sports, and pharmaceutical industries, are looking bright.

\section{References}

Tsai, S. (2018). Introduction to composite materials. Routledge.

Buckley, J. D., \& Edie, D. D. (Eds.). (1993). Carbon-carbon materials and composites. William Andrew.

Harish, S., Michael, D. P., Bensely, A., Lal, D. M., \&Rajadurai, A. (2009). Mechanical property evaluation of natural fiber coir composite. Materials characterization, 60(1), 44-49.

Abilash, N., \&Sivapragash, M. (2013). Environmental benefits of eco-friendly natural fiber reinforced polymeric composite materials. International Journal of Application or Innovation in Engineering \& Management, 2(1), 53-59.

Burgueno, R., Quagliata, M. J., Mohanty, A. K., Mehta, G., Drzal, L. T., \&Misra, M. (2004). Load-bearing natural fiber composite cellular beams and panels. Composites Part A: applied science and manufacturing, 35(6), 645-656.

Al-Oqla, F. M., \&Sapuan, S. M. (2017). Materials selection for natural fiber composites. Woodhead Publishing.

ThyavihalliGirijappa, Y. G., MavinkereRangappa, S., Parameswaranpillai, J., \&Siengchin, S. (2019). Natural fibers as sustainable and renewable resource for development of eco-friendly composites: a comprehensive review. Frontiers in Materials, 6, 226.

Khan, T., Hameed Sultan, M. T. B., \&Ariffin, A. H. (2018). The challenges of natural fiber in manufacturing, material selection, and technology application: a review. Journal of Reinforced Plastics and Composites, 37(11), 770-779. 
Mohammed, L., Ansari, M. N., Pua, G., Jawaid, M., \& Islam, M. S. (2015). A review on natural fiber reinforced polymer composite and its applications. International Journal of Polymer Science, 2015.

Corbière-Nicollier, T., Laban, B. G., Lundquist, L., Leterrier, Y., Månson, J. A., \& Jolliet, O. (2001). Life cycle assessment of biofibers replacing glass fibers as reinforcement in plastics. Resources, Conservation and recycling, 33(4), 267-287.

Clemons, C. M., \& Caulfield, D. F. (2005). Natural fibers. Functional fillers for plastics. Weinheim: WileyVCH, 2005: pages [195]-206.

Mitra, B. C. (2014). Environment friendly composite materials: biocomposites and green composites. Defence Science Journal, 64(3), 244.

Bar, M., Alagirusamy, R., \& Das, A. (2018). Advances in Natural Fiber Reinforced Thermoplastic Composite Manufacturing: Effect of Interface and Hybrid Yarn Structure on Composite Properties. In Advances in Natural Fiber Composites (pp. 99-117). Springer, Cham.

Shah, D. U., Schubel, P. J., \& Clifford, M. J. (2013). Modelling the effect of yarn twist on the tensile strength of unidirectional plant fiber yarn composites. Journal of Composite Materials, 47(4), 425-436.

Mallick PK. Fiber-reinforced composites: materials, manufacturing, and design. CRC press; 2007 Nov 19.

Goutianos, S., Peijs, T., Nystrom, B., \&Skrifvars, M. (2006). Development of flax fiber based textile reinforcements for composite applications. Applied composite materials, 13(4), 199-215.

Erden S, Ho K. Fiber reinforced composites.[In] Fiber Technology for Fiber-Reinforced Composites [Ed] ÖzgürSeydibeyoğlu M, Mohanty AK, Misra M.

Al-Oqla FM, Sapuan SM. Natural fiber reinforced polymer composites in industrial applications: feasibility of date palm fibers for sustainable automotive industry. Journal of Cleaner Production. 2014 Mar 1;66:34754.

Mohammed L, Ansari MN, Pua G, Jawaid M, Islam MS. A review on natural fiber reinforced polymer composite and its applications. International Journal of Polymer Science. 2015 Oct 1;2015.

Cristaldi G, Latteri A, Recca G, Cicala G. Composites based on natural fiber fabrics. Woven fabric engineering. 2010 Aug 18;17:317-42.

Pickering, K.L.; Efendy, M.G.A.; Le, T.M. A review of recent developments in natural fiber composites and their mechanical performance. Compos. Part A Appl. Sci. Manuf. 2016, 83, 98-112.

Chermoshentseva AS, Pokrovskiy AM, Bokhoeva LA. The behavior of delaminations in composite materialsexperimental results. InIOP Conference Series: Materials Science and Engineering 2016 Feb 1 (Vol. 116, No. 1, p. 012005). IOP Publishing.

Mitra BC. Environment friendly composite materials: biocomposites and green composites. Defence Science Journal. 2014 May 1;64(3):244.

Dicker MP, Duckworth PF, Baker AB, Francois G, Hazzard MK, Weaver PM. Green composites: A review of material attributes and complementary applications. Composites part A: applied science and manufacturing. 2014 Jan 1;56:280-9.

Imre B, Pukánszky B. Compatibilization in bio-based and biodegradable polymer blends. European Polymer Journal. 2013 Jun 1;49(6):1215-33.

Peças P, Carvalho H, Salman H, Leite M. Natural fiber composites and their applications: a review. Journal of Composites Science. 2018 Dec;2(4):66.

Awang N, Ismail AF, Jaafar J, Matsuura T, Junoh H, Othman MH, Rahman MA. Functionalization of polymeric materials as a high performance membrane for direct methanol fuel cell: A review. Reactive and Functional Polymers. 2015 Jan 1;86:248-58.

Rohan T, Tushar B, Mahesha GT. Review of natural fiber composites. InIOP Conference Series: Materials Science and Engineering 2018 Feb 1 (Vol. 314, No. 1, p. 012020). IOP Publishing.

Bleys G. Technology watch: biopolymers.

Dicker MP, Duckworth PF, Baker AB, Francois G, Hazzard MK, Weaver PM. Green composites: A review of material attributes and complementary applications. Composites part A: applied science and manufacturing. 2014 Jan 1;56:280-9.

Endres HJ, Siebert-Raths A, Behnsen H, Schulz C. Biopolymers: Facts and Statistics. IfBBInstitutfürBiokunststoffe und Bioverbundwerkstoffe: Hannover, Germany. 2016:2363-8559.

Peças P, Carvalho H, Salman H, Leite M. Natural fiber composites and their applications: a review. Journal of Composites Science. 2018 Dec;2(4):66.

Koronis G, Silva A, Fontul M. Green composites: A review of adequate materials for automotive applications. Composites Part B: Engineering. 2013 Jan 1;44(1):120-7.

Smith GF. New developments in producing more functional and sustainable composites. Management, Recycling and Reuse of Waste Composites. 2010 Jan 1:425-39.

Jeyapragash R, Srinivasan V, Sathiyamurthy SJ. Mechanical properties of natural fiber/particulate reinforced epoxy composites-A review of the literature. Materials Today: Proceedings. 2020 Jan 1;22:1223-7. 
Balla VK, Kate KH, Satyavolu J, Singh P, Tadimeti JG. Additive manufacturing of natural fiber reinforced polymer composites: Processing and prospects. Composites Part B: Engineering. 2019 Oct 1;174:106956.

Amiandamhen SO, Meincken M, Tyhoda L. Natural fiber modification and its influence on fiber-matrix interfacial properties in biocomposite materials. Fibers and Polymers. 2020 Apr;21(4):677-89.

Hasan KM, Horváth PG, Alpár T. Potential natural fiber polymeric nanobiocomposites: A review. Polymers. 2020 May;12(5):1072.

Shea A, Lawrence M, Walker P. Hygrothermal performance of an experimental hemp-lime building. Construction and Building Materials. 2012 Nov 1;36:270-5.

Hussain A, Calabria-Holley J, Lawrence M, Ansell MP, Jiang Y, Schorr D, Blanchet P. Development of novel building composites based on hemp and multi-functional silica matrix. Composites Part B: Engineering. 2019 Jan 1;156:266-73.

Ayrilmis N, Jarusombuti S, Fueangvivat V, Bauchongkol P, White RH. Coir fiber reinforced polypropylene composite panel for automotive interior applications. Fibers and Polymers. 2011 Oct;12(7):919-26.

Muzyczek M. The use of flax and hemp for textile applications. InHandbook of natural fibers 2020 Jan 1 (pp. 147-167). Woodhead Publishing.

Zhang Y, Li Y, Ma H, Yu T. Tensile and interfacial properties of unidirectional flax/glass fiber reinforced hybrid composites. Composites Science and Technology. 2013 Nov 14;88:172-7.

Yan L, Chouw N, Jayaraman K. Flax fiber and its composites-A review. Composites Part B: Engineering. 2014 Jan 1;56:296-317.

Kamaraj M, Dodson EA, Datta S. Effect of graphene on the properties of flax fabric reinforced epoxy composites. Advanced Composite Materials. 2020 Sep 2;29(5):443-58.

Battegazzore D, Frache A, Abt T, Maspoch ML. Epoxy coupling agent for PLA and PHB copolymer-based cotton fabric bio-composites. Composites Part B: Engineering. 2018 Sep 1;148:188-97.

Holt GA, Chow P, Wanjura JD, Pelletier MG, Wedegaertner TC. Evaluation of thermal treatments to improve physical and mechanical properties of bio-composites made from cotton byproducts and other agricultural fibers. Industrial Crops and Products. 2014 Jan 1;52:627-32.

Shibata M, Teramoto N, Nakamura T, Saitoh Y. All-cellulose and all-wood composites by partial dissolution of cotton fabric and wood in ionic liquid. Carbohydrate polymers. 2013 Nov 6;98(2):1532-9.

Shen M, Wang L, Long JJ. Biodegumming of ramie fiber with pectinases enhanced by oxygen plasma. Journal of Cleaner Production. 2015 Aug 15;101:395-403.

Hasan KM, Horváth PG, Alpár T. Potential natural fiber polymeric nanobiocomposites: A review. Polymers. 2020 May;12(5):1072.

Mahmud S, Pervez MN, Hasan KF, Taher MA, Liu HH. In situ synthesis of green AgNPs on ramie fabric with functional and catalytic properties. Emerging Materials Research. 2019 Oct 30;8(4):623-33.

Yu T, Ren J, Li S, Yuan H, Li Y. Effect of fiber surface-treatments on the properties of poly (lactic acid)/ramie composites. Composites Part A: Applied Science and Manufacturing. 2010 Apr 1;41(4):499-505.

Zhu Z, Hao M, Zhang N. Influence of contents of chemical compositions on the mechanical property of sisal fibers and sisal fibers reinforced PLA composites. Journal of Natural Fibers. 2018 May 3.

Cisneros-López EO, Pérez-Fonseca AA, Fuentes-Talavera FJ, Anzaldo J, González-Núñez R, Rodrigue D, Robledo-Ortíz JR. Rotomolded polyethylene-agave fiber composites: Effect of fiber surface treatment on the mechanical properties. Polymer Engineering \& Science. 2016 Aug;56(8):856-65.

Langhorst AE, Burkholder J, Long J, Thomas R, Kiziltas A, Mielewski D. Blue-agave fiber-reinforced polypropylene composites for automotive applications. BioResources. 2018;13(1):820-35.

Annandarajah C, Li P, Michel M, Chen Y, Jamshidi R, Kiziltas A, Hoch R, Grewell D, Montazami R. Study of agave fiber-reinforced biocomposite films. Materials. 2019 Jan;12(1):99.

Aliotta L, Gigante V, Coltelli MB, Cinelli P, Lazzeri A, Seggiani M. Thermo-mechanical properties of PLA/short flax fiber biocomposites. Applied Sciences. 2019 Jan;9(18):3797.

Zhang H, Liu D, Huang T, Hu Q, Lammer H. Three-Dimensional Printing of Continuous Flax Fiber-Reinforced Thermoplastic Composites by Five-Axis Machine. Materials. 2020 Jan;13(7):1678.

Mahdi E, Dean A. The effect of filler content on the tensile behavior of polypropylene/cotton fiber and poly (vinyl chloride)/cotton fiber composites. Materials. 2020 Jan;13(3):753.

$\mathrm{Ng}$ WK, Johar M, Israr HA, Wong KJ. A review on the interfacial characteristics of natural fiber reinforced polymer composites. Interfaces in Particle and Fiber Reinforced Composites. 2020 Jan 1:163-98.

Farahbakhsh N, Shahbeigi-Roodposhti P, Sadeghifar H, Venditti RA, Jur JS. Effect of isolation method on reinforcing capability of recycled cotton nanomaterials in thermoplastic polymers. Journal of Materials Science. 2017 May 1;52(9):4997-5013.

Battegazzore D, Abt T, Maspoch ML, Frache A. Multilayer cotton fabric bio-composites based on PLA and PHB copolymer for industrial load carrying applications. Composites Part B: Engineering. 2019 Apr 15;163:761-8. 
Das M. Bamboo fiber-based polymer composites. InComposite Materials 2017 (pp. 627-645). Springer, Berlin, Heidelberg.

Lokesh P, Kumari TS, Gopi R, Loganathan GB. A study on mechanical properties of bamboo fiber reinforced polymer composite. Materials Today: Proceedings. 2020 Jan 1;22:897-903.

Saxena M, Pappu A, Haque R, Sharma A. Sisal fiber based polymer composites and their applications. InCellulose fibers: Bio-and nano-polymer composites 2011 (pp. 589-659). Springer, Berlin, Heidelberg.

Chaitanya S, Singh I, Song JI. Recyclability analysis of PLA/Sisal fiber biocomposites. Composites Part B: Engineering. 2019 Sep 15;173:106895.

Munde YS, Ingle RB, Siva I. Investigation to appraise the vibration and damping characteristics of coir fiber reinforced polypropylene composites. Advances in Materials and Processing Technologies. 2018 Oct 2;4(4):639-50.

Mishra S, Nayak C, Sharma MK, Dwivedi UK. Influence of coir fiber geometry on mechanical properties of SiC filled epoxy composites. Silicon. $2021 \mathrm{Feb} ; 13(2): 301-7$.

Choi HY, Lee JS. Effects of surface treatment of ramie fibers in a ramie/poly (lactic acid) composite. Fibers and Polymers. 2012 Feb;13(2):217-23.

Djafar Z, Renreng I, Jannah M. Tensile and Bending Strength Analysis of Ramie Fiber and Woven Ramie Reinforced Epoxy Composite. Journal of Natural Fibers. 2020 Feb 15:1-2.

Chandar JV, Shanmugan S, Murugan P, Mutharasu D, Sudesh K. Structural analysis of ZnO nanoparticles reinforced $\mathrm{P}$ (3HB-co-15 mol\% 3HHx) bioplastic composite. Journal of Polymers and the Environment. 2017 Dec;25(4):1251-61.

Dixit S, Goel R, Dubey A, Shivhare PR, Bhalavi T. Natural fiber reinforced polymer composite materials-a review. Polymers from renewable resources. 2017 May;8(2):71-8.

Nassar A, Nassar E. Effect of fiber orientation on the mechanical properties of multi layers laminate nanocomposites. Heliyon. 2020 Jan 1;6(1):e03167.

Crosky A, Soatthiyanon N, Ruys D, Meatherall S, Potter S. Thermoset matrix natural fiber-reinforced composites. Natural Fiber Composites. 2014 Jan 1:233-70.

Mohammed L, Ansari MN, Pua G, Jawaid M, Islam MS. A review on natural fiber reinforced polymer composite and its applications. International Journal of Polymer Science. 2015 Oct 1;2015.

Ghosh AK, Dwivedi M. Processability in Open Mould Processing of Polymeric Composites. InProcessability of Polymeric Composites 2020 (pp. 179-203). Springer, New Delhi.

Hosseini SB. Natural fiber polymer nanocomposites. Fiber-Reinforced Nanocomposites: Fundamentals and Applications. 2020 Jan 1:279-99.

Getme AS, Patel B. A Review: Bio-fiber's as reinforcement in composites of polylactic acid (PLA). Materials Today: Proceedings. 2020 Jan 1;26:2116-22.

Miao C, Hamad WY. Cellulose reinforced polymer composites and nanocomposites: a critical review. Cellulose. 2013 Oct;20(5):2221-62.

Cotica LF, Garcia A, Polli AD, Bini RD, de Chaves T, de Oliveira Junior VA, Pamphile JA. Nanobiocomposites: Synthesis and Environmental Applications. InFungal Nanobionics: Principles and Applications 2018 (pp. 1-19). Springer, Singapore.

Valentina I, Haroutioun A, Fabrice L, Vincent V, Roberto P. Poly (lactic acid)-based nanobiocomposites with modulated degradation rates. Materials. 2018 Oct;11(10):1943.

Kausar A. A review of high performance polymer nanocomposites for packaging applications in electronics and food industries. Journal of Plastic Film \& Sheeting. 2020 Jan;36(1):94-112.

Adamu M, Rahman MR, Hamdan S. Bamboo Nanocomposite: Impact of Poly (Ethylene-alt-Maleic Anhydride) and Nanoclay on Physicochemical, Mechanical, and Thermal Properties. BioResources. 2020;15(1):33146.

Saba N, Paridah MT, Abdan K, Ibrahim NA. Physical, structural and thermomechanical properties of oil palm nano filler/kenaf/epoxy hybrid nanocomposites. Materials Chemistry and Physics. 2016 Dec 1;184:64-71.

Sinha RK, Sridhar K, Purohit R, Malviya RK. Effect of nano SiO2 on properties of natural fiber reinforced epoxy hybrid composite: A review. Materials Today: Proceedings. 2020 Jan 1;26:3183-6.

Lazzara G, Cavallaro G, Panchal A, Fakhrullin R, Stavitskaya A, Vinokurov V, Lvov Y. An assembly of organic-inorganic composites using halloysite clay nanotubes. Current Opinion in Colloid \& Interface Science. 2018 May 1;35:42-50.

Blanco I. The rediscovery of POSS: A molecule rather than a filler. Polymers. 2018 Aug;10(8):904.

Mohajerani A, Burnett L, Smith JV, Kurmus H, Milas J, Arulrajah A, Horpibulsuk S, Abdul Kadir A. Nanoparticles in construction materials and other applications, and implications of nanoparticle use. Materials. 2019 Jan;12(19):3052.

Marquis DM, Guillaume E, Chivas-Joly C. Properties of Nanollers in Polymer. Nanocomposites and polymers with analytical methods. 2011 Aug 9:261.

Campilho RD, editor. Natural fiber composites. CRC Press; 2015 Nov 5. 
Sanadi AR, Caulfield DF, Jacobson RE, Rowell RM. Renewable agricultural fibers as reinforcing fillers in plastics: Mechanical properties of kenaf fiber-polypropylene composites. Industrial \& Engineering Chemistry Research. 1995 May;34(5):1889-96.

Mohanty AK, Misra M, Drzal LT, editors. Natural fibers, biopolymers, and biocomposites. CRC press; 2005 Apr 8.

Faruk O, Bledzki AK, Fink HP, Sain M. Biocomposites reinforced with natural fibers: 2000-2010. Progress in polymer science. 2012 Nov 1;37(11):1552-96.

Baeurle SA, Hotta A, Gusev AA. On the glassy state of multiphase and pure polymer materials. Polymer. 2006 Aug 9;47(17):6243-53.

Sinha R. Outlines of polymer technology: manufacture of polymers. PHI Learning Pvt. Ltd.; 2004 Oct 1.

Mohammad NA. Synthesis, characterization and properties of the new unsaturated polyester resins for composite applications. MARA University of Technology. 2007 Apr:45-56.

Iijima T, Tochimoto T, Tomoi M. Modification of epoxy resins with poly (aryl ether ketone) s. Journal of applied polymer science. 1991 Nov 5;43(9):1685-92.

Thakur S, Chaudhary J, Sharma B, Verma A, Tamulevicius S, Thakur VK. Sustainability of bioplastics: Opportunities and challenges. Current opinion in Green and Sustainable chemistry. 2018 Oct 1;13:68-75.

Kuruppalil Z. Green plastics: an emerging alternative for petroleum-based plastics. Int J Eng Res Innov. 2011;3(1):59-64.

Sundarraj AA, Ranganathan TV. A review on cellulose and its utilization from agro-industrial waste. Drug Invent. Today. 2018 Jan 1;10(1):89-94.

Fortea-Verdejo M, Bumbaris E, Burgstaller C, Bismarck A, Lee KY. Plant fiber-reinforced polymers: where do we stand in terms of tensile properties?. International Materials Reviews. 2017 Nov 17;62(8):441-64.

Gurunathan T, Mohanty S, Nayak SK. A review of the recent developments in biocomposites based on natural fibers and their application perspectives. Composites Part A: Applied Science and Manufacturing. 2015 Oct 1;77:1-25.

Sanjay MR, Madhu P, Jawaid M, Senthamaraikannan P, Senthil S, Pradeep S. Characterization and properties of natural fiber polymer composites: A comprehensive review. Journal of Cleaner Production. 2018 Jan 20;172:566-81.

Dittenber DB, GangaRao HV. Critical review of recent publications on use of natural composites in infrastructure. Composites Part A: applied science and manufacturing. 2012 Aug 1;43(8):1419-29.

Pickering KL, Efendy MA, Le TM. A review of recent developments in natural fiber composites and their mechanical performance. Composites Part A: Applied Science and Manufacturing. 2016 Apr 1;83:98-112.

Shubhra QT, Alam AK, Quaiyyum MA. Mechanical properties of polypropylene composites: A review. Journal of thermoplastic composite materials. 2013 Apr;26(3):362-91.

Langhorst AE, Burkholder J, Long J, Thomas R, Kiziltas A, Mielewski D. Blue-agave fiber-reinforced polypropylene composites for automotive applications. BioResources. 2018;13(1):820-35.

Fuentes CA, Brughmans G, Tran LQ, Dupont-Gillain C, Verpoest I, Van Vuure AW. Mechanical behaviour and practical adhesion at a bamboo composite interface: Physical adhesion and mechanical interlocking. Composites Science and Technology. 2015 Mar 10;109:40-7.

Thomason JL. Dependence of interfacial strength on the anisotropic fiber properties of jute reinforced composites. Polymer Composites. 2010 Sep;31(9):1525-34.

Thomason J, Jenkins P, Yang L. Glass fiber strength - A review with relation to composite recycling. Fibers. 2016 Jun;4(2):18.

Akampumuza O, Wambua PM, Ahmed A, Li W, Qin XH. Review of the applications of biocomposites in the automotive industry. Polymer Composites. 2017 Nov;38(11):2553-69.

Ishikawa T, Amaoka K, Masubuchi Y, Yamamoto T, Yamanaka A, Arai M, Takahashi J. Overview of automotive structural composites technology developments in Japan. Composites Science and Technology. 2018 Feb 8;155:221-46.

Koronis G, Silva A, Fontul M. Green composites: A review of adequate materials for automotive applications. Composites Part B: Engineering. 2013 Jan 1;44(1):120-7.

Ahmad F, Choi HS, Park MK. A review: natural fiber composites selection in view of mechanical, light weight, and economic properties. Macromolecular materials and engineering. 2015 Jan;300(1):10-24.

Khalfallah M, Abbès B, Abbès F, Guo YQ, Marcel V, Duval A, Vanfleteren F, Rousseau F. Innovative flax tapes reinforced Acrodur biocomposites: a new alternative for automotive applications. Materials \& Design. 2014 Dec 1;64:116-26.

Kong C, Lee H, Park H. Design and manufacturing of automobile hood using natural composite structure. Composites Part B: Engineering. 2016 Apr 15;91:18-26.

Badji C, Beigbeder J, Garay H, Bergeret A, Benezet JC, Desauziers V. Exterior and under glass natural weathering of hemp fibers reinforced polypropylene biocomposites: Impact on mechanical, chemical, microstructural and visual aspect properties. Polymer Degradation and Stability. 2018 Feb 1;148:104-16. 
Panaitescu DM, Vuluga Z, Ghiurea M, Iorga M, Nicolae C, Gabor R. Influence of compatibilizing system on morphology, thermal and mechanical properties of high flow polypropylene reinforced with short hemp fibers. Composites Part B: Engineering. 2015 Feb 1;69:286-95.

Yahaya R, Sapuan SM, Jawaid M, Leman Z, Zainudin ES. Effect of fiber orientations on the mechanical properties of kenaf-aramid hybrid composites for spall-liner application. Defence Technology. 2016 Feb $1 ; 12(1): 52-8$.

Yahaya R, Sapuan SM, Jawaid M, Leman Z, Zainudin ES. Effects of kenaf contents and fiber orientation on physical, mechanical, and morphological properties of hybrid laminated composites for vehicle spall liners. Polymer composites. 2015 Aug;36(8):1469-76.

Gardner DJ, Aydemir D, Kızıltaş A, Erbaş Kızıltaş E, Gündüz G. Heat treated wood-nylon 6 composites.

Krishnan GS, Babu LG, Pradhan R, Kumar S. Study on tribological properties of palm kernel fiber for brake pad applications. Materials Research Express. 2019 Dec 9;7(1):015102.

Farid M, Purniawan A, Rasyida A, Ramadhani M, Komariyah S. Improvement of acoustical characteristics: wideband bamboo based polymer composite. InIOP Conference Series: Materials Science and Engineering 2017 Jul 1 (Vol. 223, No. 1, p. 012021). IOP Publishing.

Mohammed L, Ansari MN, Pua G, Jawaid M, Islam MS. A review on natural fiber reinforced polymer composite and its applications. International Journal of Polymer Science. 2015 Oct 1;2015.

Mostafa M, Uddin N. Experimental analysis of Compressed Earth Block (CEB) with banana fibers resisting flexural and compression forces. Case Studies in Construction Materials. 2016 Dec 1;5:53-63.

Akubueze EU, Ezeanyanaso CS, Muniru SO, Igwe CC, Nwauzor GO, Ugoh U, Nwaze IO, Mafe O, Nwaeche FC. Reinforcement of plaster of Paris (POP) for suspended ceilings applications using kenaf bast fiber. Current Journal of Applied Science and Technology. 2019 Aug 1:1-6.

Dahy H. Natural Fiber-Reinforced Polymer Composites (NFRP) Fabricated from Lignocellulosic Fibers for Future Sustainable Architectural Applications, Case Studies: Segmented-Shell Construction, Acoustic Panels, and Furniture. Sensors. 2019 Jan;19(3):738.

Tavares TD, Antunes JC, Ferreira F, Felgueiras HP. Biofunctionalization of natural fiber-reinforced biocomposites for biomedical applications. Biomolecules. 2020 Jan;10(1):148.

Reddy KS, Singla H. Optimization of woven jute/glass fiber-reinforced polyester hybrid composite solar parabolic trough collector. InIOP Conference Series: Materials Science and Engineering 2017 Jul 1 (Vol. 222, No. 1, p. 012016). IOP Publishing.

Morris RH, Geraldi NR, Stafford JL, Spicer A, Hall J, Bradley C, Newton MI. Woven Natural Fiber Reinforced Composite Materials for Medical Imaging. Materials. 2020 Jan;13(7):1684.

Yusup EM, Mahzan S, Kamaruddin MA. Natural Fiber Reinforced Polymer for the Application of Sports Equipment using Mold Casting Method. InIOP Conference Series: Materials Science and Engineering 2019 Mar 1 (Vol. 494, No. 1, p. 012040). IOP Publishing.

Zhang Y, Mao T, Wu H, Cheng L, Zheng L. Carbon Nanotubes Grown on Flax Fabric as Hierarchical All-Carbon Flexible Electrodes for Supercapacitors. Advanced Materials Interfaces. 2017 May;4(9):1601123.

Yuan H, Wang F, Li S, Lin Z, Huang J. A cellulose substance derived nanofibrous CoS-nanoparticle/carbon composite as a high-performance anodic material for lithium-ion batteries. New Journal of Chemistry. 2020;44(5):1846-57.

Xia C, Ren H, Shi SQ, Zhang H, Cheng J, Cai L, Chen K, Tan HS. Natural fiber composites with EMI shielding function fabricated using VARTM and $\mathrm{Cu}$ film magnetron sputtering. Applied Surface Science. 2016 Jan 30;362:335-40.

Xia C, Yu J, Shi SQ, Qiu Y, Cai L, Wu HF, Ren H, Nie X, Zhang H. Natural fiber and aluminum sheet hybrid composites for high electromagnetic interference shielding performance. Composites Part B: Engineering. 2017 Apr 1;114:121-7.

Muessig J. Influence of fiber fineness on the properties of natural fiber composites. InProceedings, 4th International Wood and Natural Fiber Composites Symposium Kassel/Germany 2002 Apr 10.

Witayakran S, Smitthipong W, Wangpradid R, Chollakup R, Clouston PL. Natural fiber composites: review of recent automotive trends.

Huda MS, Drzal LT, Ray D, Mohanty AK, Mishra M. Natural-fiber composites in the automotive sector. InProperties and performance of natural-fiber composites 2008 Jan 1 (pp. 221-268). Woodhead Publishing.

Carus M, Eder A, Dammer L, Korte H, Scholz L, Essel R, Breitmayer E, Barth M. Wood-Plastic Composites (WPC) and Natural Fiber Composites (NFC). Nova-Institute: Hürth, Germany. 2015;16. 